\title{
Consumption of alcoholic beverages and subjective health in Spain
}

P Guallar-Castillón, F Rodríguez-Artalejo, L Díez Gañán, J R Banegas Banegas, P Lafuente Urdinguio, R Herruzo Cabrera

\begin{abstract}
Study objective-To examine the relation between alcohol and main alcoholic beverage consumption and subjective health in Spain.

Design-Logistic regression analysis using a cross sectional survey based on self reported data on alcohol and alcoholic beverage consumption, subjective health and the principal confounding factors (age, sex, civil status, educational level, job status, social support, region of residence, size of town or city, tobacco consumption, physical activity during leisure time and work hours, and chronic
\end{abstract} disease).

Setting-The 1993 Spanish National

Health Survey.

Participants-A 19573 person sample, representative of the non-institutionalised Spanish population aged 16 years and over.

Main results-Among Spaniards, 31.4\% reported their health as suboptimal (fair, poor or very poor) and $56.9 \%$ consumed alcohol regularly, with the majority having a preference for wine. Light (1-2 drinks per day) or moderate consumption (3-4 drinks per day) was the most frequent pattern. After adjusting for confounding factors, a negative dose-response relation was observed between consumption of total alcohol, wine and beer, and prevalence of suboptimal health (linear trend: $p<0.001$ for total alcohol, $p=0.023$ for wine, and $p=0.030$ for beer). In contrast, for consumption of spirits the prevalence of ill health in moderate drinkers was lower than in non-drinkers, with no clear relation at higher consumption. While persons reporting a preference for wine had a lower frequency of suboptimal health than did abstainers, they showed no difference in frequency of subjective ill health with respect to persons with preference for other types of drink or no preference whatsoever.

Conclusions-The higher the consumption of total alcohol, wine and beer, the lower the prevalence of suboptimal health. These results differ from those obtained in several Nordic countries, where a "J shaped" relation has been observed for total alcohol and wine, and suggest that the relation between alcohol consumption and subjective health may be different in Mediterranean countries.

(F Epidemiol Community Health 2001;55:648-652)
Alcohol raises mortality from cirrhosis of the liver, certain tumours and violent causes, among other causes of death, and is responsible for $6 \%$ of all deaths in Spain. ${ }^{12}$ However, the overall impact of alcohol on health is not clear. Moderate consumption of alcohol among adults and the elderly is associated with reduced risk of coronary disease and ischaemic stroke. ${ }^{3}$ There is also some evidence that moderate alcohol consumption may contribute to the lower cardiovascular mortality of the northern regions of Spain. ${ }^{45}$ Furthermore, consumption of alcohol is associated with reduced use of healthcare services (medical visits, hospital admissions and hospital emergencies) by the Spanish population. ${ }^{6}$

To obtain a balanced view of the effect of alcohol on health, overall measures of health can be used, such as subjective evaluation of the general state of health. Not only does subjective health correlate well with other direct and indirect measures of health (functional disability, ${ }^{7}$ health related quality of life), ${ }^{89}$ it is also a good predictor of mortality. ${ }^{10-13}$

Studies of the relation between alcohol and subjective health have mostly been undertaken in Nordic countries ${ }^{14-17}$ and in Holland, ${ }^{18}$ yet this relation may be different in Spain and other Mediterranean countries. In Spain, consumption of alcohol takes place principally at mealtime (in contrast with the Nordic pattern), and wine continues to be the chief source of alcohol (again, in contrast with the Nordic countries, ${ }^{14}$ where beer and spirits predominate). Moreover, Spain's low general and cardiovascular mortality and most characteristic lifestyle habits (diet, moderate physical activity, frequent sun exposure, warm temperatures, a high degree of family-based and a low degree of community-based social support), might well lead to the determinants of subjective health being different to those at work in Nordic countries. ${ }^{14}$

Accordingly, this paper examines the relation between alcohol and main alcoholic beverage consumption and subjective health in Spain.

\section{Methods}

Data were drawn from the 1993 Spanish National Health Survey (SNHS) (Encuesta Nacional de Salud de España), which covered a random sample of 19573 persons representative of the non-institutionalised Spanish population aged 16 years and over, stratified by sex, age, and town or city of residence. ${ }^{19}$

SNHS data were collected through home interviews, with alcohol consumption assessed with a frequency-quantity scale, adapted to alcoholic beverage consumption patterns in 
Spain. Participants furnished information on the usual frequency and quantity of beer, wine and spirits consumed during the preceding year, through answering two questions, the first of which was: "How often do you usually consume alcoholic beverages?". Possible replies for beer, wine and spirits were: (a) 3-4 times a day; (b) twice a day; (c) once a day; (d) 5-6 times a week; (e) 3-4 times a week; (f) once-twice a week; (g) 2-3 times a month; (h) once a month; (i) less than once a month but more than once a year; and, (k) never. The second question was: "How many glasses or drinks do you usually have at any one time?". Total alcohol consumption was taken as the sum of the values for the three types of beverage, assuming that: a $250 \mathrm{ml}$ glass of beer contained $8 \mathrm{~g}$ of alcohol; a $120 \mathrm{ml}$ glass of wine, $11.5 \mathrm{~g}$ of alcohol; and a typical "drink" of spirits, $16 \mathrm{~g}$ of alcohol. Alcohol intake was expressed in units of drink containing $10 \mathrm{~g}$ of alcohol. ${ }^{20}$

A non-drinker (abstainer) was defined as any person who had not consumed alcohol or had done so less than once a month during the year immediately preceding the interview. Preference for wine was defined as consumption of a quantity of wine that was at least $20 \%$ greater than that of other alcoholic beverages, and vice versa for beer and spirits.

The SNHS measured subjective health with the following question: "In the last twelve months, would you say that your state of health has been very good, good, fair, poor or very poor?". Only one answer was allowed from the five health status categories given. In addition, the SNHS supplied self reported information on the variables of adjustment included in the analysis.

The survey response rate was $100 \%$, as the sampling design provided for replacement of the original subject by another, in cases where they could not be located at home or refused to be interviewed. Even so, the percentage of initial non-participation in the survey was only $8.5 \%$.

To calculate the prevalence of suboptimal health (fair, poor or very poor health), survey subjects were weighted by the inverse of the sampling fraction. ${ }^{21}$ Using unconditional multiple logistic regression, odds ratios for suboptimal health by intake of alcohol and alcoholic beverages were calculated, with adjustment for sampling stratification variables ${ }^{22}$ and other confounding factors. The following variables were controlled for (categories of each variable): age (years: 16-24, 25-44, 45-64, over 64); sex (female, male); civil status (married, unmarried); educational level (no formal education, primary education, secondary education, university education); job status (unemployed, retired, active, student); social support (living alone, living with others); region of residence (each of Spain's 17 administrative regions); size of town or city (inhabitants: under $10000 ; 10000-100000 ; 100001-$ $400000 ; \quad 400001-1000000 ; \quad$ over 1000000 ); tobacco consumption (noncurrent smoker, ex-smoker, $>0-10$ cigarettes/ day, 11-20 cigarettes/day, over 20 cigarettes/ day); physical activity during leisure time (high, moderate, low, sedentary); physical activity during work hours (high, moderate, low, sedentary); and chronic disease (yes, no). Chronic disease included arterial hypertension, hypercholesterolaemia, diabetes, coronary disease, asthma or chronic bronchitis, stomach ulcer and allergy.

Alcohol intake and consumption of alcoholic beverages were modelled using dummy variables, while to study the dose-response relation, variables were introduced into the models on a continuous scale. Analyses for any particular beverage are adjusted for consumption of the other two types of beverages, because variables for the consumption of each of the three types of beverages were simultaneously introduced into the models. Lastly, the interaction between alcohol consumption and age, sex, tobacco consumption and presence of chronic disease was examined with terms that were the product of alcohol and these variables.

Analyses were performed using the Epiinfo $^{21}$ and SAS ${ }^{23}$ software packages.

\section{Results}

Of the total of 19573 subjects, 11144 (56.9\%) consumed alcohol regularly, with the majority expressing a preference for wine. Light (1-2 drinks per day) or moderate consumption (3-4 drinks per day) was the most frequent pattern (table 1). Alcohol consumption was higher in men than in women, and decreased with age. Consumption of alcohol was also higher in the upper socioeconomic strata, and among people with active employment, who lived in small towns (less than 10000 inhabitants), and had no chronic diseases. In addition, alcohol intake increased with tobacco consumption and physical activity at work. However, alcohol

Table 1 Distribution of the 19573 subjects covered by the National Health Survey, by presence of suboptimal health and alcohol consumption: Spain, 1993

\begin{tabular}{|c|c|c|c|}
\hline & \multicolumn{2}{|c|}{$\begin{array}{l}\text { Number of subjects with } \\
\text { suboptimal health }\end{array}$} & \multirow[b]{2}{*}{ Total subjects } \\
\hline & Number & $\%$ & \\
\hline \multicolumn{4}{|c|}{ Total alcohol (units/day) } \\
\hline 0 & 3388 & 40.20 & 8429 \\
\hline$>0-2$ & 1776 & 25.60 & 6937 \\
\hline $3-4$ & 454 & 22.68 & 2002 \\
\hline $5-6$ & 229 & 22.58 & 1016 \\
\hline$\geqslant 7$ & 291 & 24.53 & 1189 \\
\hline \multicolumn{4}{|l|}{ Wine (drinks/day) } \\
\hline 0 & 592 & 20.61 & 2872 \\
\hline$>0-2$ & 1528 & 25.57 & 5975 \\
\hline $3-4$ & 326 & 27.67 & 1178 \\
\hline $5-6$ & 194 & 26.83 & 725 \\
\hline$\geqslant 7$ & 111 & 28.29 & 393 \\
\hline \multicolumn{4}{|l|}{ Beer (drinks/day) } \\
\hline 0 & 1276 & 31.67 & 4029 \\
\hline$>0-2$ & 1317 & 21.05 & 6260 \\
\hline $3-4$ & 104 & 18.48 & 560 \\
\hline $5-6$ & 33 & 20.69 & 160 \\
\hline$\geqslant 7$ & 21 & 15.31 & 134 \\
\hline \multicolumn{4}{|l|}{ Spirits (drinks/day) } \\
\hline 0 & 1678 & 29.70 & 5649 \\
\hline$>0-2$ & 818 & 19.05 & 4294 \\
\hline $3-4$ & 147 & 20.02 & 733 \\
\hline $5-6$ & 51 & 22.50 & 224 \\
\hline$\geqslant 7$ & 59 & 24.08 & 243 \\
\hline \multicolumn{4}{|c|}{ Preference for the consumption of: } \\
\hline Wine & 1521 & 29.70 & 5121 \\
\hline Beer & 596 & 20.95 & 2846 \\
\hline Spirits & 495 & 19.73 & 2511 \\
\hline No preference & 138 & 20.82 & 665 \\
\hline
\end{tabular}


consumption did not change materially with civil status, social support or physical activity during leisure time.

Of the total of study subjects, 6138 (31.4\%) reported their health as suboptimal. Consumers of any amount of alcohol showed a lower frequency of ill health than did abstainers. This association was also observed in consumers of beer and spirits (table 1). However, frequency of suboptimal health was higher among wine drinkers than among non-wine drinkers. This is because wine drinkers are much older than their non-wine drinking counterparts and, consequently, chronic diseases and perceived ill health tend to be more frequent among the former (data not shown).

After adjustment for the principal confounding factors, a negative dose-response relation was observed between total alcohol intake and prevalence of suboptimal health (linear trend p: <0.001). This relation was observed also for wine (mainly on adjusting for age) and beer. In contrast, for consumption of spirits the prevalence of ill health was lower in moderate drinkers than in non-drinkers, but it was found no clear relation with subjective health at higher consumption (fig 1). These results were not substantially modified by determinants of subjective health, such as age, sex, tobacco consumption and presence of chronic disease. Controlling for factors such as chronic conditions, social support and job status might be an overadjustment of the relation between alcohol and subjective health, because they could act as intermediary factors. Therefore, we also run the models excluding the variables for chronic disease, social support and job status. However, the results of the new models were very similar to those with full adjustment.
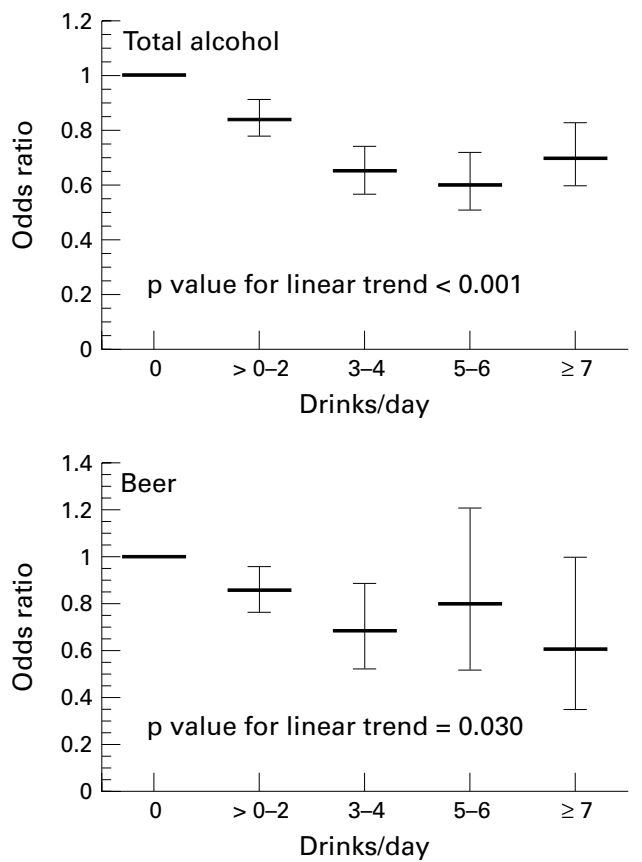

KEY POINTS

- Alcohol raises mortality from cirrhosis, certain tumours and violent causes, but it could also reduce risk of cardiovascular disease.

- A balanced view of the effect of alcohol on health can be obtained from overall measures of health, such as subjective health.

- In Spain, the higher the consumption of total alcohol, wine and beer, the lower the prevalence of suboptimal subjective health.

- The relation between alcohol and subjective health may be vary from Mediterranean to Nordic countries, where a "J shaped" relation has been observed.

While persons reporting a preference for wine had a lower frequency of suboptimal health than did abstainers, they displayed no difference in frequency of subjective ill health with respect to persons having a preference for other types of drink or no preference whatsoever (table 2). These results were observed after adjusting for total alcohol intake and other confounding factors, and were not substantially modified by sex, tobacco consumption or presence of chronic disease (tables 2 and 3). An interaction with age was observed $(\mathrm{p}<0.001)$, inasmuch as a preference for wine tended to be associated with a lower frequency of ill health among persons under the age of 45 years, with the relation becoming inverted among those aged 45 years and over (table 2).
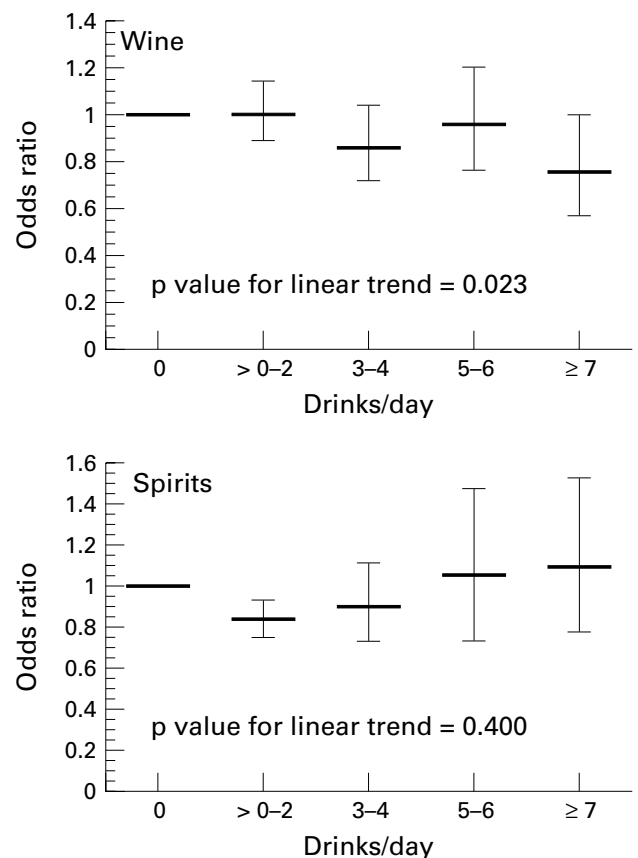

Figure 1 Odds ratios for suboptimal health, by total alcohol consumption and consumption of different alcoholic beverages. Odds ratios are adjusted for age, sex, presence of chronic disease, civil status, social support, educational level, tobacco consumption, physical activity at work, physical activity during leisure time, job status, region of residence and size of town or city. Analyses for any particular beverage are adjusted for consumption of the other two types of alcohol beverage. 
Table 2 Odds ratios $(O R)^{\star}$ for suboptimal health, by alcoholic beverage preference, sex and age: Spain, 1993

\begin{tabular}{llllll}
\hline Preference & $\begin{array}{l}\text { Total } \text { OR } \\
(95 \% \mathrm{CI})\end{array}$ & $\begin{array}{l}\text { Men OR } \\
(95 \% \mathrm{CI})\end{array}$ & $\begin{array}{l}\text { Women OR } \\
(95 \% \mathrm{CI})\end{array}$ & $\begin{array}{l}\text { 16-44 years OR } \\
(95 \% \mathrm{CI})\end{array}$ & $\begin{array}{l}\text { 45 years and over } \\
\text { OR }(95 \% \mathrm{CI})\end{array}$ \\
\hline Wine & 1.00 & 1.00 & 1.00 & 1.00 & 1.00 \\
Beer & $1.04(0.92,1.18)$ & $0.98(0.82,1.16)$ & $1.08(0.90,1.30)$ & $1.05(0.89,1.25)$ & $0.95(0.78,1.16)$ \\
Spirits & $1.08(0.95,1.23)$ & $1.01(0.85,1.21)$ & $1.16(0.95,1.42)$ & $1.11(0.93,1.32)$ & $0.97(0.78,1.20)$ \\
No preference & $1.11(0.90,1.37)$ & $1.13(0.87,1.45)$ & $0.99(0.64,1.48)$ & $1.38(1.05,1.79)$ & $0.73(0.50,1.03)$ \\
Abstainers & $1.28(1.16,1.40)$ & $1.35(1.17,1.55)$ & $1.17(1.03,1.33)$ & $1.17(1.01,1.36)$ & $1.33(1.18,1.49)$ \\
\hline
\end{tabular}

*Adjusted for age and sex (where appropriate), presence of chronic disease, civil status, social support, educational level, tobacco consumption, physical activity during work hours, physical activity during leisure time, job status, region of residence, size of town or city and total alcohol consumption.

Table 3 Odds ratios (OR) * for suboptimal health, by alcoholic beverage preference, tobacco consumption and presence of chronic disease: Spain, 1993

\begin{tabular}{llllll}
\hline Preference & $\begin{array}{l}\text { No current smokers } \\
\text { OR }(95 \% \mathrm{CI})\end{array}$ & $\begin{array}{l}\text { Ex-smokers OR } \\
(95 \% \mathrm{CI})\end{array}$ & $\begin{array}{l}\text { Smokers OR } \\
(95 \% \mathrm{CI})\end{array}$ & $\begin{array}{l}\text { Presence of chronic } \\
\text { disease OR }(95 \% \mathrm{CI})\end{array}$ & $\begin{array}{l}\text { Absence of chronic } \\
\text { disease OR (95\% CI) }\end{array}$ \\
\hline Wine & 1.00 & 1.00 & 1.00 & 1.00 & 1.00 \\
Beer & $1.07(0.88,1.31)$ & $0.63(0.44,0.89)$ & $1.06(0.87,1.27)$ & $0.91(0.73,1.15)$ & $1.06(0.91,1.23)$ \\
Spirits & $1.22(0.97,1.52)$ & $0.91(0.64,1.28)$ & $0.98(0.81,1.18)$ & $1.23(0.98,1.55)$ & $1.00(0.85,1.17)$ \\
No preference & $0.93(0.59,1.44)$ & $0.73(0.42,1.23)$ & $1.28(0.96,1.69)$ & $1.08(0.72,1.59)$ & $1.11(0.86,1.43)$ \\
Abstainers & $1.27(1.11,1.44)$ & $1.37(1.09,1.72)$ & $1.13(0.95,1.34)$ & $1.44(1.24,1.66)$ & $1.19(0.06,1.34)$ \\
\hline
\end{tabular}

*Adjusted for age, sex, presence of chronic disease (where appropriate), civil status, social support, educational level, tobacco consumption (where appropriate), physical activity during work hours, physical activity during leisure time, job status, region of residence, size of town or city and total alcohol consumption.

\section{Discussion}

We have observed that, in Spain, the higher the consumption of alcohol, wine and beer, the lower the prevalence of suboptimal health. Moreover, there is no difference in the frequency of subjective ill health between wine drinkers and people who prefer other beverages. These results differ from those obtained in population samples in several Nordic countries, and suggest that the relation between alcohol consumption and subjective health may be different in Mediterranean countries.

In a cross sectional study covering persons aged 25-64 years in three areas of Finland, a "J shaped" relation was observed between alcohol intake and subjective suboptimal (that is, fair or poor) health. ${ }^{14}$ Furthermore, compared with non-wine drinkers, frequency of suboptimal health was lower in drinkers of 1-4 glasses of wine, yet higher in drinkers of 10 or more glasses of wine or spirits. ${ }^{15}$ In another cross sectional study conducted in the Copenhagen city area, the above "J shaped" relation was confirmed for total alcohol consumption. ${ }^{16}$ When the analysis was broken down by alcoholic beverage, wine consumption alone plotted a "J shaped" relation with subjective suboptimal health; in contrast, subjective health reported by moderate drinkers of beer and spirits proved no better than that reported by abstainers. Finally, in a cross sectional study on a representative population sample in Sweden, no clear relation was observed between alcohol consumption and subjective health, ${ }^{17}$ whereas another study in the south east of Holland reported results similar to ours-that is, as alcohol consumption increases the frequency of ill health decreases. ${ }^{18}$ However, this Dutch study failed to furnish results by type of beverage.

With regard to our results on beverage preference, these too were not consistent with those obtained in Copenhagen, where wine drinkers reported better subjective health than beer drinkers. ${ }^{16}$

It is possible that the discrepancies between our results and those of other studies may, in part, be attributable to methodological differences. However, despite important differences in their respective ways of measuring alcohol consumption, response rates, population type (rural or urban) and control of confounding factors, the Nordic studies ${ }^{14-17}$ none the less yielded similar results. In fact, the study by Manderbacka et $a l^{17}$ in Sweden also observed a "J shaped" relation between alcohol consumption and subjective health, before adjustment for health problems and functional disabilities, which could be intermediary factors between alcohol and subjective health and, therefore, could not be considered confounders. It is therefore plausible that the relation under review may vary across countries, in line with cultural elements and lifestyle habits.

Our study has some advantages and limitations. Among the advantages are the large size of the sample and that it is representative of the Spanish population as a whole. Moreover, in the analysis a greater number of possible confounding factors were controlled for than in previous studies. ${ }^{14-16}$

As to the limitations, firstly it is a cross sectional study and, therefore, it cannot establish the direction of the observed relation between alcohol and subjective health. Furthermore, the SNHS does not distinguish between lifetime abstainers and ex-drinkers; there is always the possibility that subjective ill health may have induced a halt or a decline in alcohol consumption, which might explain the presence of worse subjective health among abstainers. However, this limitation did not impede the observation of a similar prevalence of ill health in abstainers and in consumers of over two drinks/day of spirits in our study, and a "J shaped" relation with total alcohol, wine and spirits in others. ${ }^{16}$ Secondly, self reported alcohol consumption tends to underestimate real consumption, particularly for heavy drinkers, and may lead to misclassification errors. ${ }^{24} 25$ The presumable effect of such errors is to attenuate any relation found, yet there is evidence that it exerts only a small influence on 
effect estimators. ${ }^{26}$ Lastly, although we adjusted for a great number of variables in the analysis, not all possible predictors of subjective health were taken into account. Notwithstanding this, the results were also observed after adjusting for the presence of chronic disease, hence making it reasonable to assume that part of the alcohol-subjective health relation is not mediated by chronic diseases, whether alcohol or non-alcohol related.

As to the study's practical implications, the negative association between alcohol and suboptimal health should not be used to promote even the moderate consumption of alcoholic beverages, as this could lead to a rise in heavy drinking ${ }^{27}$ and its associated morbidity and mortality burden. ${ }^{28}$ In addition, some of the limitations of current studies, particularly those with a cross sectional design, suggest the need for prospective studies on this topic.

We thank the Ministry of Public Health for providing the Spanish National Health Survey data in computerised format.

Funding: this study was financed in part by grant 99/712 from the Fondo de Investigación Sanitaria (Health Research Fund). Conflicts of interes: none.

1 Yañez JL, Del Río MC, Álvarez FJ. Alcohol-related mortality in Spain. Alcohol Clin Exp Res 1993;2:253-5.

2 Prada Puentes C, del Río Gracia MC, Yañez JL, et al. Mortalidad relacionada con el consumo de alcohol en España. Gac Sanit 1996;10:161-8.

3 Thun MJ, Peto R, Lopez AD, et al. Alcohol consumption and mortality among middle-aged and elderly U.S. adults. N Engl f Med 1997;337:1705-14.

4 Rodríguez Artalejo F, Banegas Banegas JR, García Colmenero $\mathrm{C}$, et al. Lower consumption of wine and fish as a possible explanation for higher ischaemic heart disease mortality in Spain's Mediterranean region. Int $f$ Epidemiol 1996;25:1196-201.

5 Rodríguez Artalejo F, Guallar Castillón P, Gutiérrez-Fisac $\mathrm{JL}$, et al. Socio-economic level, sedentary lifestyle and wine $\mathrm{JL}$, et al. Socio-economic level, sedentary lifestyle and wine consumption as possible explanations for geographical distribution of cerebrovas

6 Rodríguez Artalejo F, Andrés Manzano B, Guallar-Castillón $\mathrm{P}$, et al. The association of tobacco and alcohol consumption with the use of health-care services in Spain. Prev Med 2000;31:554-61

7 Laforge RG, Williams GD, Parker DA, et al. Alcoholic beverage type, recall period effects and functional disability: evidence from the 1983 NHIS. Drug Alcohol Depend 1990; 25:257-72.

8 Bergner M, Bobbitt RA, Pollard WE, et al. The Sickness Impact Profile: validation of a health status measure. Med Care 1976;14:57-67.

9 Brazier JE, Harper R, Jones NM, et al. Validating the SF-36 health survey questionnaire: new outcome measure for primary care. BMF 1992;305:160-4.

10 Mossey JM, Shapiro E. Self-rated health: a predictor of mortality among the elderly. Am f Public Health 1982;72: $800-8$.

11 Wannamethee G, Shaper AG. Self-assessment of health status and mortality in middle-aged British men. Int 7 Epidemiol 1991;20:239-45.

12 Idler EL, Benyamini Y. Self-rated health and mortality: a review of twenty-seven community studies. F Health Soc Behav 1997;38:21-37.

13 Engstrom G, Hedblad B, Janzon L. Subjective well-being ssociated with improved survival in smoking and hypertensive men. F Cardiovasc Risk 1999;6:257-61

14 Poikolainen K, Vartiainen E, Korhonen H. Alcohol intake and subjective health. Am F Epidemiol 1996;144:346-50.

15 Poikolainen K, Vartiainen E. Wine and good subjective health. Am ₹ Epidemiol 1999; 150:47-50.

16 Gronbaek M, Mortensen EL, Mygind K, et al. Beer, wine, spirits and subjective health. $\mathcal{F}$ Epidemiol Community Health 1999;53:721-4.

17 Manderbacka K, Lundberg O, Martikainen P. Do risk factors and health behaviours contribute to self-ratings of health? Soc Sci Med 1999;48:1713-20.

18 Mackenbach JP, van den Bos J, Joung IMA, et al. The determinants of excellent health: different from the determinants of ill health? Int F Epidemiol 1994;23:1273-81.

19 Ministerio de Sanidad y Consumo. Encuesta Nacional de Salud de España 1993. Madrid: Ministerio de Sanidad y Consumo, 1995.

20 Rodríguez-Martos Dauer A, Gual Solé A, Llopis Llácer JJ. La "unidad de bebida estándar" como registro simplificado del consumo de bebidas alcohólicas y su determinación en España. Med Clin (Barc) 1999;112:446-50.

21 Sullivan K, Klasbbek W, Chen M, et al. CSAMPLE: Analizar datos procedentes de muestras complejas. In: Dean AG, Dean JA, Coulombier D, et al. Epi Info 6.03. Atlanta: Centers for Disease Control and Prevention, 1996.

22 Korn EL, Graubard BI. Epidemiologic studies utilizing surveys. Accounting for the sampling design. Am F Public Health 1991;81:1166-73.

23 SAS/STAT. Guide for personal computers, version 6.12. Cary, NC: SAS Institute, 1996.

24 Midanik L. The validity of self-reported alcohol consumption: a review of the literature $\mathrm{Br} \mathcal{7}$ Addict 1982;77:357-82

25 Gutiérrez-Fisac JL. Indicadores de consumo de alcohol en España. Med Clin (Barc) 1995;104:544-50.

26 Verdek PH, Buitendijk SE, Veerlove-Vanhorick SP. Differential misclassification of alcohol and cigarette consumption by pregnancy outcome. Int 7 Epidemiol 1994;23:1218-25.

27 Rodríguez-Artalejo F, de Andrés Manzano B, GuallarCastillón $\mathrm{P}$, et al. Association of moderate consumption of alcohol with rates of heavy drinking and abstinence in Spain. Alcohol Clin Exp Res 1999;23:1502-6.

28 Edwards G, Andersen P, Babor TF, et al. Alcohol policy and the public good. Oxford: Oxford University Press, 1994. 